fall is peculiar to our population. Himal et $a l^{4}$ recently reported a similar decrease in Montreal in the number of patients with acute peptic ulceration secondary to ulcerogenic drugs.

Analysis of our figures over the past year has shown one death in 107 admissions, a mortality rate of under $1 \%$. We believe that our improved results are due to several factors, ranging from early diagnosis and vigorous resuscitation to strict criteria for surgical intervention. Possibly the most important factor has been the formation of a unit with a combined medical and surgical approach in which patients are cared for by the same personnel familiar with all aspects of upper gastrointestinal haemorrhage.

We therefore conclude that a prospective system of management with regular review of results and formation of a unit certainly improve mortality rate in patients with upper gastrointestinal bleeding.

We wish to thank Sister A Stewardson for her help with data collection, and Ms E Kaminski for her valuable secretarial work.

\section{References}

1 Schiller, K F R, Truelove, S C, and Williams, D G, British Medical fournal, 1970, 2, 7.

2 Medical fournal of Australia, 1973, 2, 256.

3 Paull, A, Vandeth, A G, and Grant, A K, Australian and New Zealand Fournal of Medicine, 1974, 4, 12.

${ }^{4}$ Himal, H S, Perrault, C, and Mzabi, R, Surgery, 1978, 84, 448.

(Accepted 20 March 1979)

\title{
Extradural haematoma: effect of delayed treatment
}

\author{
A D MENDELOW，M Z KARMI，K S PAUL，G A G FULLER，F J GILLINGHAM
}

British Medical fournal, 1979, 1, 1240-1242

\section{Summary and conclusions}

The case records of patients with extradural haematomas treated in the Lothian region during 1951-60 and 1968-77 were analysed to assess the effect of delay in treatment on morbidity and mortality. Delay was defined as the time from deterioration in level of consciousness to surgical evacuation of clot. There were 83 supratentorial extradural haematomas unassociated with intradural clot or contusion. The mean delay in patients who died was 15.7 hours, while in good-quality survivors the mean delay was 1.9 hours. Mortality decreased from $33.3 \%$ during 1951-60 to 8.9\% during 1968-77. In addition, good recovery without morbidity occurred in $40.7 \%$ of patients in the earlier period and $67.9 \%$ in the later period. Mean delays from deterioration in level of consciousness to operation were 9.8 and 2.4 hours in the earlier and later periods respectively.

The results emphasise the need for immediate operation in patients deteriorating with extradural haematomas. Direct admission of all head-injured patients to a head and spinal injuries unit staffed by neurosurgeons resulted in minimal delay times as well as a reduction in morbidity and mortality.

\section{Introduction}

Delay in removing expanding intracranial haematomas is an important factor contributing to increased morbidity and mortality in head injuries, and this is particularly so with extradural haematomas. ${ }^{12}$ The effect of delay on outcome in cases of extradural haematoma, however, has not been measured. This is particularly important now that frequent use of the CAT scan is being recommended in head injuries ${ }^{3}$ because unnecessary delays in its use may occur when there is a clear-cut clinical

Head and Spinal Injuries Unit, Department of Surgical Neurology, Royal Infirmary, Edinburgh EH3 9YW

A D MENDELOW, PHD, FRCS, registrar

M Z KARMI, FRCS, registrar

K S PAUL, MS, registrar

G A G FULLER, FRCS, registrar

F J GILLINGHAM, FRCS, FRCPED, professor and head of department

indication for immediate operation. Furthermore, knowing the time that can be spared for such investigation and transferring patients with head injuries may aid the planning and organisation of neurosurgical services. In the Lothian region before 1960 (the first decade studied here) head-injured patients were admitted to general surgical beds, and after that time (second decade studied) they were admitted direct to the head and spinal injuries unit under the care of neurosurgeons. To assess the effect this has had on outcome in patients with extradural haematomas we have compared the results obtained during the decades 1951-60 and 1968-77.

\section{Patients and methods}

We examined the case records of all patients with extradural haematomas treated in the Edinburgh area during 1951-60 and 1968-77. An extradural haematoma was considered to be significant when thicker than $1.5 \mathrm{~cm}$. Small haematomas associated with depressed fractures of the skull were excluded. Particular attention was paid to time relations, which were obtained from the records as well as operating-theatre books, anaesthetic charts, nursing records, and admission books. Delay was defined as the time from the first recorded deterioration in level of consciousness to operation. Delays were recorded as delay in hospital and total delay, some patients having deteriorated before admission. Delay in hospital thus represents that part of the total delay that occurred either in the department of surgical neurology or in other wards in the same hospital but after a neurosurgical opinion was available or had been requested, or both. Such delays occurred before a neurosurgical admission ward was established at the Edinburgh Royal Infirmary for admission of all head injuries.

Lucid interval was defined as the time from the injury or recovery from initial unconsciousness, whichever was the shorter, to subsequent deterioration in consciousness. Results were classified according to outcome at the last available assessment and graded as follows: $O$, full social and economic independence; $\mathrm{A}$, slightly disabled; $\mathrm{B}$, disabled but independent; $C$, disabled and dependent; $D$, death.

Statistics-Delay times are expressed as means $\pm S E$ of mean. Mean values were compared with use of Wilcoxon's rank sum test. ${ }^{4}$ Numerical results were compared by $\chi^{2}$ analysis. ${ }^{5} \mathrm{~A}$ significant difference was accepted when $\mathrm{P}<0.05$.

\section{Results}

Out of 145 patients with a significant extradural haematoma, 50 had an associated intradural haematoma or contusion determined radiologically, at operation, or at necropsy. In seven of the remaining $95 \stackrel{\rightleftharpoons}{\rightleftharpoons}$ cases we could not obtain all the relevant time relations, and in a further five the extradural haematoma lay within the posterior fossa. There were thus 83 pure supratentorial extradural haematomas un- 
associated with intradural clot or contusion with adequately documented time relations, and they are considered here. Twenty-seven cases occurred during 1951-60 and 56 during 1968-77. Altogether 20 patients were unconscious from the time of injury, 29 had a typical lucid interval, and 34 had no initial loss of consciousness (fig 1).

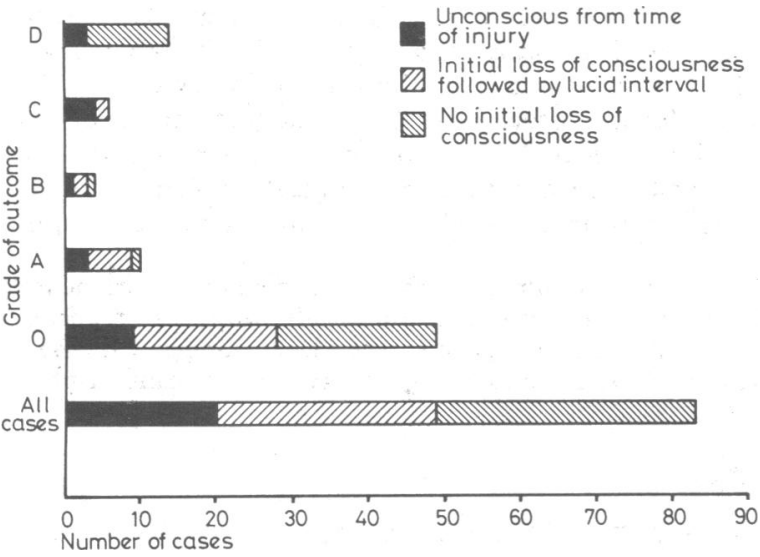

FIG 1-Patterns of presentation and outcome in all 83 patients with extradural haematoma treated in the two periods. (See text for key to grades of outcome.)

TABLE I-Outcome in the two periods studied. Figures are numbers of patients (percentages in parentheses)

\begin{tabular}{|c|c|c|c|c|}
\hline & $\begin{array}{l}\text { Normal } \\
\text { (grade O) }\end{array}$ & $\begin{array}{c}\text { Morbidity } \\
\text { (grades } \mathbf{A}+\mathbf{B}+\mathbf{C})\end{array}$ & $\begin{array}{c}\text { Death } \\
\text { (grade D) }\end{array}$ & $\begin{array}{c}\text { All } \\
\text { patients }\end{array}$ \\
\hline $1951-60$ & $11(40 \cdot 7)$ & $7(25 \cdot 9)\left\{\begin{array}{l}\mathrm{A}=1(3 \cdot 7) \\
\mathrm{B}=3(11 \cdot) \\
\mathrm{C}=3(11 \cdot 1)\end{array}\right.$ & $9(33.3)$ & $27(100 \cdot 0)$ \\
\hline $1968-77$ & $38(67 \cdot 9)$ & $13(23 \cdot 2)\left\{\begin{array}{l}\mathrm{A}=9(16 \cdot 1) \\
\mathrm{B}=1(1 \cdot 8) \\
\mathrm{C}=3(5 \cdot 4)\end{array}\right.$ & $5(8.9)$ & $56(100 \cdot 0)$ \\
\hline Total & $49(59 \cdot 0)$ & $20(24 \cdot 1)$ & $14(16.9)$ & $83(100 \cdot 0)$ \\
\hline
\end{tabular}

Significance of difference between periods: $\chi^{2}=8.77 ; \mathrm{P}<0.025 ; \mathrm{DF}=2$.

Table I gives the results in the two periods. The mortality rate was much lower in the second decade $(8.9 \%)$ than in the first $(33.3 \%)$. There was also a lower proportion of severely disabled survivors (grades $\mathbf{B}+\mathbf{C}$ ) in the later period.

To determine whether delay contributed to morbidity and mortality the delay times of the whole group (83) were analysed. We found that the longer the delays the higher were the morbidity and mortality rates (table II; fig 2). Specifically, a delay exceeding two hours generally tended to produce poor results (table II).

The policy of admitting all head-injured patients for 24 hours to the head and spinal injuries unit was applied throughout the second decade studied but not the first. To establish whether this policy decreased delay the total delay and delay times in hospital in the two periods were compared. In the earlier period the mean total delay was $9 \cdot 8 \pm$ $6 \cdot 1$ hours and in the later period $2 \cdot 4 \pm 0.6$ hours. This difference was significant $(P<0.05)$. The mean delays in hospital during the earlier and later periods were $8 \cdot 0 \pm 6 \cdot 2$ and $1 \cdot 4 \pm 0 \cdot 5$ hours respectively. This difference approached significance $(P=0.06)$. Not unexpectedly, the policy did not influence delays in referral but rather decreased delays in hospital. Delays in referral (total delay minus delay in hospital),

TABLE II-Results in all 83 patients treated in the two periods correlated with total delay times (mean $\pm S E$ of mean)

\begin{tabular}{lccccc}
\hline & \multicolumn{6}{c}{ Grade of outcome } \\
\cline { 2 - 6 } & $\mathrm{O}$ & $\mathrm{A}$ & $\mathrm{B}$ & $\mathrm{C}$ & $\mathrm{D}$ \\
\hline Total delay (hours) & $1.9 \pm 0 \cdot 6$ & $2 \cdot 0 \pm 0 \cdot 4$ & $5 \cdot 1 \pm 1 \cdot 5$ & $8 \cdot 1 \pm 3 \cdot 5$ & $15 \cdot 7 \pm 11 \cdot 8$ \\
No $(\%)$ of patients & $49(59 \cdot 0)$ & $10(12 \cdot 0)$ & $4(4 \cdot 8)$ & $6(7 \cdot 2)$ & $14(16 \cdot 9)$
\end{tabular}

Delay times in patients with outcomes A-D $v$ delay time in patients with outcome Delay times in patients with outcomes
$\mathrm{O}: \mathrm{P}<0.05$ (Wilcoxon's rank sum test)

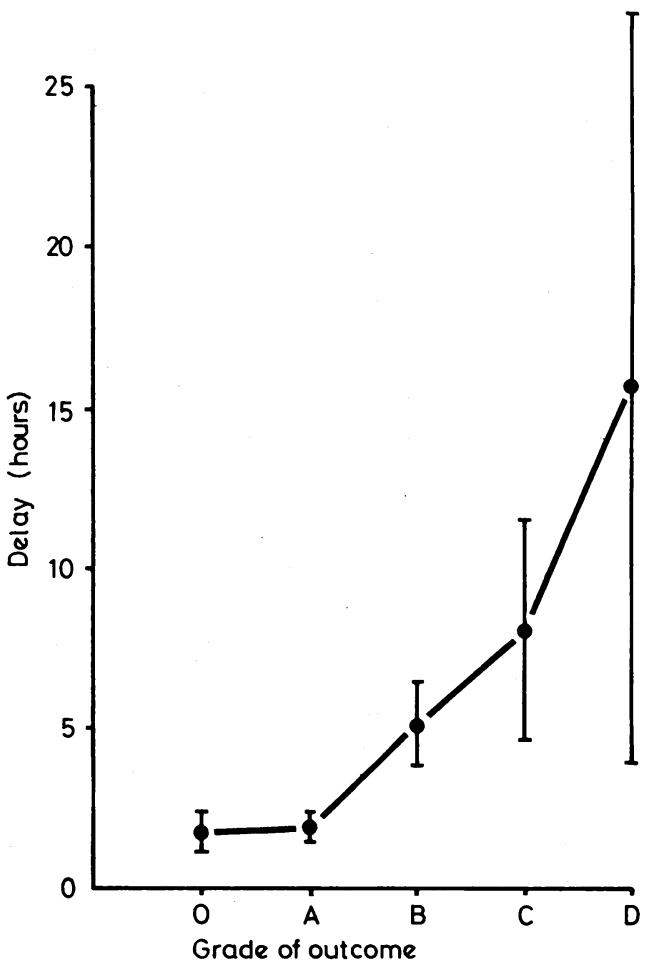

FIG 2-Mean delays ( \pm SE of mean) and outcome in all 83 patients treated in the two periods.

however, were short compared with delay in hospital and total delay in the earlier decade.

In summary, therefore: (1) delay leads to increased morbidity and mortality; (2) direct admission to neurosurgical care decreases delay times; and (3) direct admission to neurosurgical care is associated with a decline in mortality and major morbidity.

\section{Discussion}

We should emphasise that the delay times reported here start from the first recorded depression in the patient's level of response and not from the time of injury. No positive correlation was found with the injury-to-operation time. This may explain why other studies failed to show that "delay" results in increased mortality, since the delay reported was injury-to-operation time. ${ }^{6} 7$

It is difficult and perhaps invalid to compare our mortality rates with those in other reported series because of differing criteria for selection of cases. We included only supratentorial extradural haematomas thicker than $1.5 \mathrm{~cm}$. Furthermore, patients with intradural lesions were excluded. This may have introduced some selection because some patients who died had intradural lesions recorded at necropsy which may have been missed in patients who survived. This, however, should have applied to patients from both periods under study. Hence we made no attempt to correlate the mortality rates in our series with those reported elsewhere; these have varied from 5\% to $76 \%$ according to Hooper, ${ }^{8}$ who reported an average mortality rate of $23 \%$ in his series of 83 cases. This corresponds with the surgical mortality rates in most larger series of more than $\mathbf{4 0}$ cases, where mortality has ranged from $15 \cdot 6 \%$ to $40 \%{ }^{1}{ }^{7-10}$ Rather, the comparison has been made between results from one centre using the same selection criteria and definitions but with a different admission policy in the two decades studied. This in itself may introduce other variables, since advances in the non-surgical treatment of head injuries, such as anti-oedema agents and controlled ventilation, may account for the improved results in the later period. We therefore thought it necessary to look specifically at the delay times (total and in hospital) in the two periods. This analysis indicated that delays, as defined here, were longer in the earlier period (1951-60), so that delay was a 
contributing factor to the poorer results, although we do not deny that other factors may have played a part.

With these reservations the three principal conclusions may be restated in relation to extradural haematoma. (a) Delay in surgical evacuation of extradural haematomas leads to increased morbidity and mortality. Specifically it appears that delays exceeding two hours are unacceptable. (b) Direct admission of patients to neurosurgical beds from the accident and emergency unit decreased the delay time. The major delay time in the earlier period occurred in hospital and not before admission. (c) Direct admission of patients to neurosurgical beds in the later period was associated with a decline in morbidity and major mortality. That this decline was due to shorter delays is suggested by $(b)$ but may have been contributed to by other factors.

It therefore seems reasonable to conclude that direct admission of head-injured patients immediately to the primary care of the neurosurgical team is a good policy. It is, of course, possible only in cities where a neurosurgical department is immediately available and staffed to deal with head injuries in this way. Nevertheless, evacuating an extradural haematoma is not difficult, nor is diagnosing its presence and site if a history of the trend of events from injury, especially conscious level, is always obtained. A telephone consultation service round the clock must be available to district hospitals from the nearest neurosurgical department and backed up with a flying-squad service ${ }^{11}$ to deal with the more complicated problems of surgical technique. Training district hospital and accident and emergency surgeons for three to six months in a head and spinal injuries service as part of a neurosurgical department at the senior house officer/ registrar level has been part of the organisation in Edinburgh for 10 years. Its value is in no doubt.

The most important factors in reducing mortality and morbidity from extradural haematoma are thus early diagnosis and immediate action to reduce intracranial pressure by removing the clot. More often than not the diagnosis may be made clinically, and delays incurred in obtaining radiological confirmation may lead to increased morbidity and mortality if indiscriminately applied to all cases of head injury. Patients with a clear history of deterioration in level of consciousness should therefore be treated surgically with greatest urgency if the aim is to preserve intellect as well as life. From experience in the past few years the CAT scanner is of great value in patients who have remained unconscious from the time of injury or have failed to improve during observation. Such patients should not be confused with the acutely deteriorating group, who require immediate surgical decompression. Clinical vigilance remains the most important factor in all units dealing with head injuries.

We thank the consultants of the department of surgical neurology at the Royal Infirmary of Edinburgh for allowing us to report on their patients. Our thanks also go to Mrs K Mackie for help with the medical records and Miss Picton Phillipps for typing the manuscript.

\section{References}

${ }^{1}$ McKissock, W, et al, Lancet, 1960, 2, 167.

${ }^{2}$ Rose, J, Valtonon, S, and Jennett, B, British Medical fournal, 1977, 2, 615

3 Bartlett, J R, and Neil-Dwyer, G, British Medical fournal, 1978, 2, 813.

4 Documenta Geigy, Scientific Tables, 6th ed, p 191. Manchester, Geigy, 1962.

5 Armitage, P, Statistical Methods in Medical Research. Oxford, Blackwell Scientific, 1974.

${ }^{6}$ Kvarnes, T L, and Trumpy, J H, Acta Neurochirurgica, 1978, 41, 223.

' Jamieson, K G, and Yelland, J D N, fournal of Neurosurgery, 1968, 29, 13.

${ }^{8}$ Hooper, R, British fournal of Surgery, 1960, 47, 71.

9 Lewin, W, Proceedings of the Royal Society of Medicine, 1954, 47, 865.

10 Gallagher, J P, and Browder, E J, fournal of Neurosurgery, 1968, 29, 1.

11 Gillingham, F J, in Head Injuries, p 72. Edinburgh, Churchill Livingstone, 1971.

(Accepted 13 March 1979)

\title{
Hyponatraemia and severity and outcome of myocardial infarction
}

\author{
C T G FLEAR, P HILTON
}

British Medical fournal, 1979, 1, 1242-1246

\section{Summary and conclusions}

A total of 235 consecutive patients admitted to a coronary care unit were investigated for serum electrolyte and urea concentrations; activities of aspartate aminotransferase, lactate dehydrogenase, and lactate dehydrogenase isoenzymes; electrocardiographic changes; clinical state; and outcome. Hyponatraemia, hypochloraemia, and uraemia were common in patients with confirmed myocardial infarctions, the degree of infarction correlating well with all the above indices of

\footnotetext{
University Department of Clinical Biochemistry and Department of Medicine, Royal Victoria Infirmary, Newcastle upon Tyne NE1 4LP

C T G FLEAR, MD, FRCPATH, senior lecturer and consultant in clinical biochemistry

P HILTON, MB, BS, medical student (present appointment: registrar in obstetrics and gynaecology, Dryburn Hospital, Durham)
}

severity. The day-to-day variability of plasma sodium, chloride, and potassium concentrations was often increased above normal. Disturbances were greater in patients given diuretics.

It is concluded that plasma sodium concentrations fall after infarction and that the extent and duration of the fall are indices of the severity of the infarction.

\section{Introduction}

Several systemic metabolic changes have been reported to follow acute myocardial infarction in man. These include increased plasma concentrations of catecholamines, free fatty acids, cortisol, glucose, glycerol, and cyclic adenosine monophosphate; decreased triglyceride concentrations; and an initial fall in plasma insulin concentration followed by an early return to normal values. ${ }^{12}$ Most of these disturbances are also seen after injury and surgery, when hyponatraemia is common. $^{3}$ We wondered, therefore, whether plasma sodium concentrations fell after acute myocardial infarction and, if so, whether the extent of their fall was an index of severity, as has been noted in congestive heart failure. ${ }^{4-6}$

We initially carried out a preliminary retrospective study of 